\title{
Síndrome de Nicolau o embolia cutis medicamentosa: a propósito de un caso
}

\author{
Alejandra María Toro Âlvarezi'; Mónica Alejandra Gaviria Muñoz²
}

\section{RESUMEN}

El síndrome de Nicolau es una reacción cutánea poco frecuente consistente en necrosis de la piel y de los tejidos blandos, que ocurre como consecuencia de la aplicación parenteral de medicamentos. Se expone el caso de una paciente femenina de 39 años, quien presentó este síndrome luego de la aplicación intramuscular de diclofenaco y betametasona, con mejoría luego del tratamiento con pentoxifilina, iruxol y manejo quirúrgico realizado por cirugía plástica.

PalabRas ClAVE: Síndrome de Nicolau; Embolismo; Diclofenaco; Betametasona; Enfermedades cutáneas vasculares.

\section{NICOLAU SYNDROME OR EMBOLIA CUTIS MEDICAMENTOSA: A CASE REPORT}

\section{SUMMARY}

Nicolau syndrome is a rare skin reaction consisting of skin and soft tissue necrosis that occurs as a result of parenteral drug application. The case of a 39-year-old female patient who developed this syndrome after the intramuscular application of diclofenac and betamethasone, and who showed improvement after treatment with pentoxifylline, iruxol and surgical management performed by plastic surgery, is presented in the following text.

KEY WORDS: Nicolau syndrome; Embolism; Diclofenac; Betamethasone; Skin Diseases, Vascular.

1. Residente de Dermatología, Universidad Pontificia Bolivariana, Medellín, Colombia. ORCID https://orcid.org/oooo-0001-8806-0224

2. Dermatóloga, Universidad Pontificia Bolivariana, Medellín, Colombia. ORCID https://orcid.org/oooo-0001-9092-6381

Correspondencia: Alejandra María Toro Álvarez; email: alejamtoro@gmail.com

Recibido: 18/08/19; aceptado:09/06/20

Cómo citar: Toro-Álvarez AM; Gaviria-Muñoz MA. Síndrome de Nicolau o embolia cutis medicamentosa: a propósito de un caso. Rev Asoc Colomb Dermatol. Vol 28(3): julio - septiembre, 2020, 264-268. DOI: https://doi.org/10.29176/2590843X.1536

Financiación: ninguna, conflictos de interés: ninguno 


\section{INTRODUCCIÓN}

El síndrome de Nicolau, también llamado embolia cutis medicamentosa o dermatitis livedoide, es una vasculopatía poco frecuente que se produce generalmente como consecuencia de la aplicación intramuscular de un fármaco ${ }^{(1)}$, aunque se ha descrito también después de otras formas de aplicación parenteral de medicamentos $^{(2)}$, y se ha vinculado con mayor frecuencia con la administración de penicilina y antiinflamatorios no esteroideos ${ }^{(3)}$.

La presentación clínica característica consiste en dolor intenso alrededor del sitio de la inyección, seguido de eritema, dermatitis livedoide $y$, finalmente, necrosis de la piel, el tejido subcutáneo o el tejido muscular.

\section{REPORTE DE CASO}

Se presenta el caso de una paciente de 39 años, de sexo femenino, sin antecedentes patológicos de importancia, quien consultó al servicio de dermatología por la presencia de una placa necrótica en el glúteo izquierdo de 1 mes de evolución, que asoció a la aplicación de betametasona y diclofenaco intramuscular, inyección que fue automedicada. Refiere la paciente que durante la aplicación del medicamento sintió ardor y dolor intenso localizado en el sitio de la inyección, que se irradió al miembro inferior izquierdo, seguido de eritema y equimosis, con posterior aparición de necrosis.

Previo a la atención por dermatología, la paciente había recibido manejo con antibióticos orales e intravenosos y antiinflamatorios no esteroideos, sin mejoría. Tenía una ecografía de tejidos blandos que había sido realizada luego de 3 semanas de evolución del cuadro clínico y que reportaba cambios inflamatorios en el cuadrante superior externo (CSE) del glúteo izquierdo, sin colecciones ni otras anormalidades.

A la evaluación médica se encontró una placa necrótica en el CSE del glúteo izquierdo que medía $10,5 \mathrm{~cm}$ de ancho por $7 \mathrm{~cm}$ de alto, con induración y livedo reticular en la periferia, muy dolorosa a la palpación (figura 1).

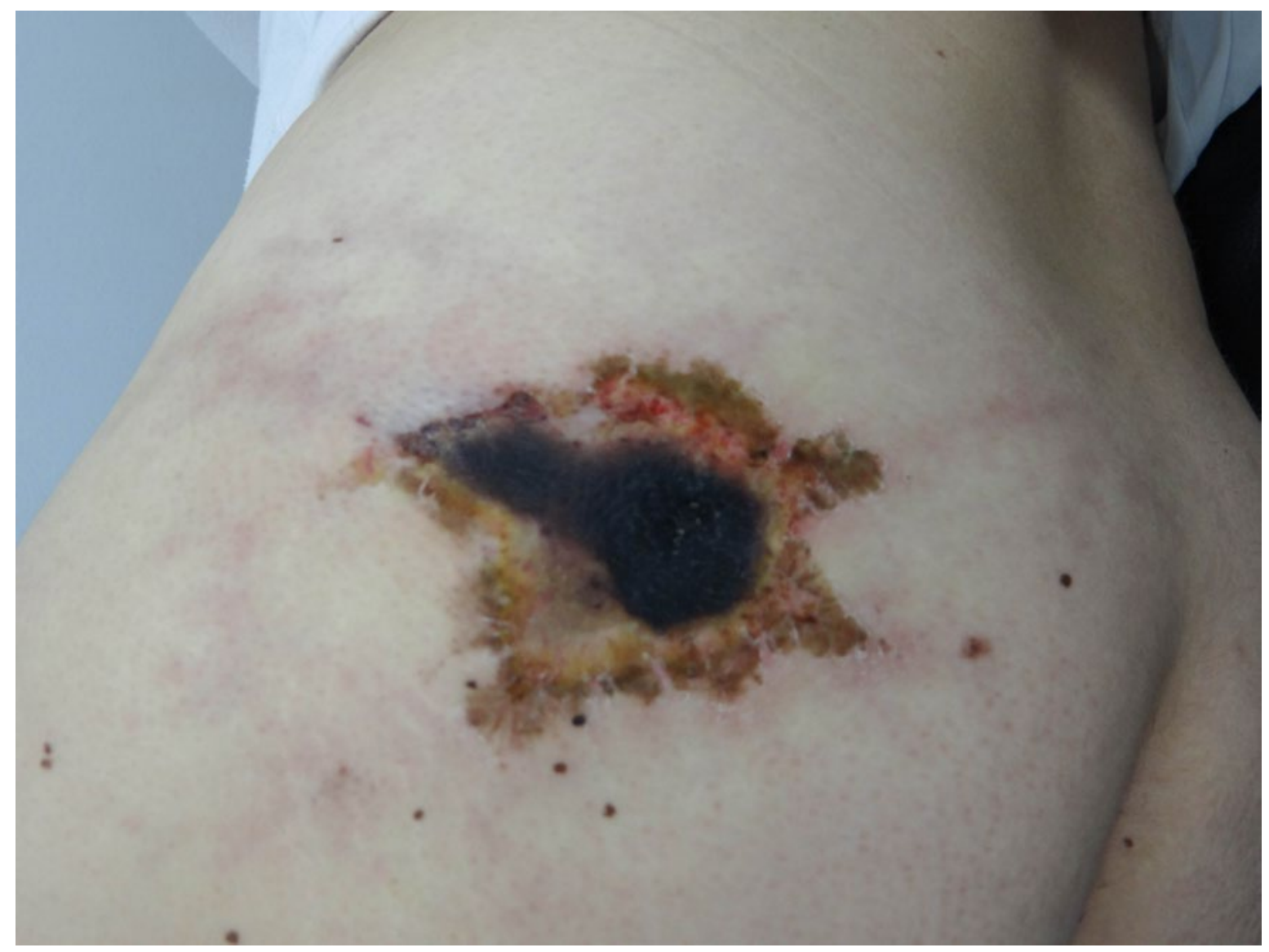

Figura 1. Placa necrótica en el glúteo izquierdo con livedo reticular en la periferia. 
Se le inició manejo con pentoxifilina en $400 \mathrm{mg}$, cada 8 horas durante 1 mes, y colagenasa (iruxol) en ungüento, una aplicación diaria. Luego de recibir este tratamiento por 2 semanas, la placa necrótica había disminuido a $7 \mathrm{~cm}$ por $4,5 \mathrm{~cm}$ y el dolor había mejorado (figura 2).
Sin embargo, por la extensión de la necrosis, fue necesaria la evaluación por cirugía plástica y el tratamiento quirúrgico (figura 3), que consistió en el desbridamiento del tejido necrótico y la reconstrucción con colgajos.

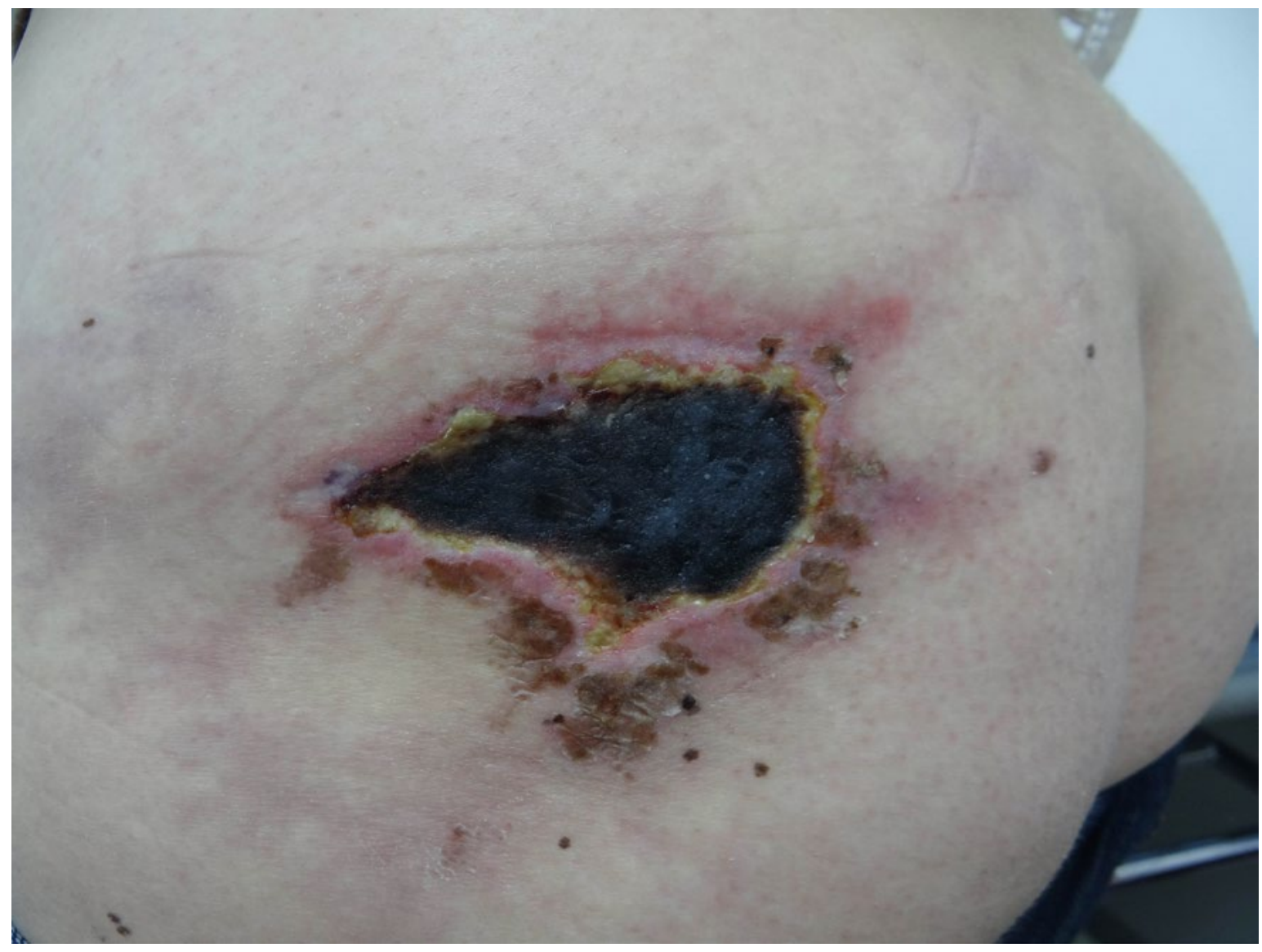

Figura 2. Evolución de la placa necrótico luego del tratamiento con pentoxifilina oral y colagenasa tópica. 


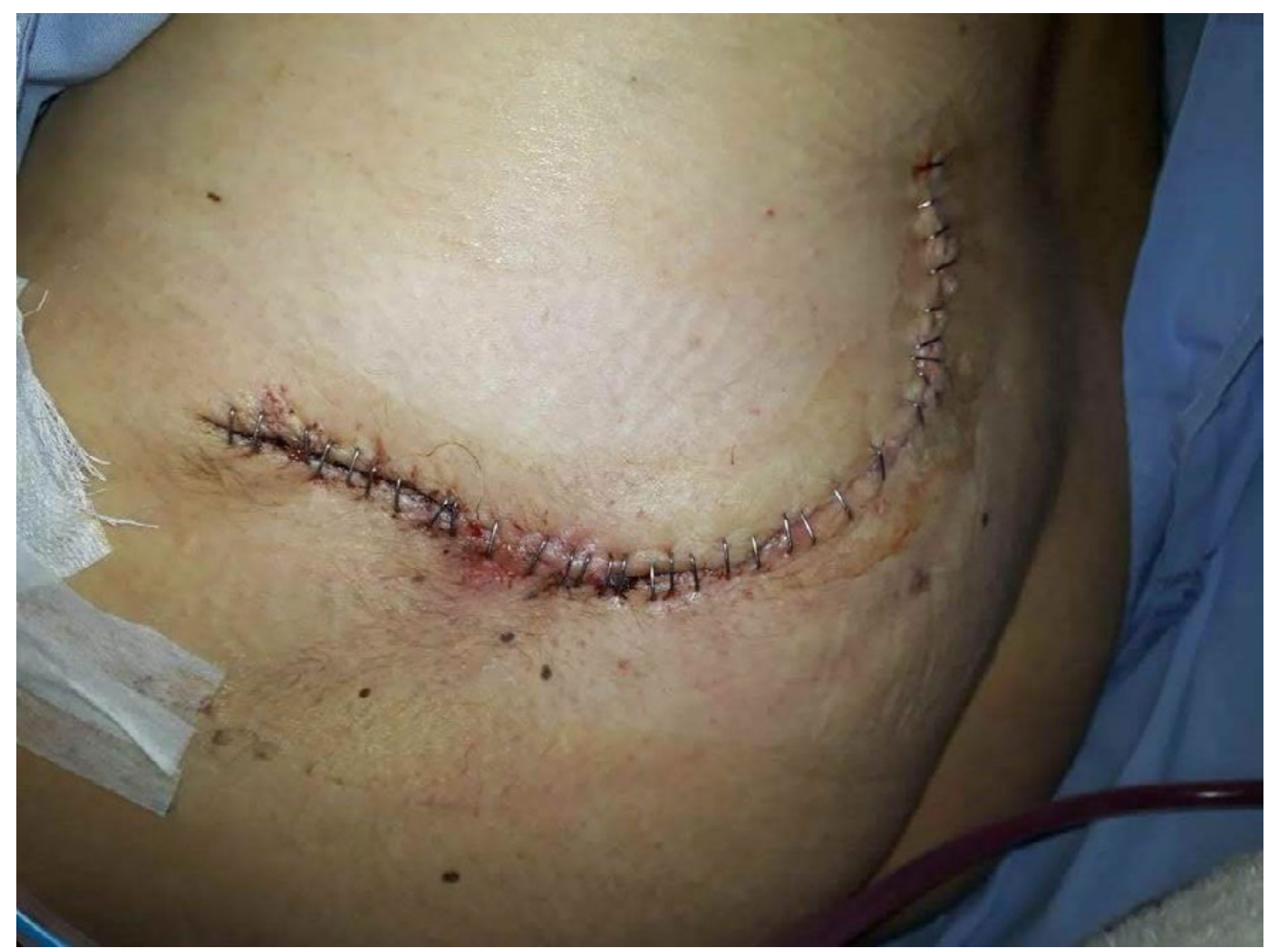

Figura 3. Desbridamiento quirúrgico de la necrosis.

\section{Puntos clave}

- El síndrome de Nicolau es una vasculopatía que ocurre como consecuencia de la aplicación parenteral de un medicamento.

- Clínicamente se caracteriza por dolor intenso, eritema, dermatitis livedoide y necrosis de la piel.

- El diagnóstico es clínico y cuanto más temprano sea diagnosticado, mejor será el pronóstico.

- El tratamiento consiste en la aplicación de vasoactivos, antibióticos sistémicos, heparina, cirugía y, en casos de necrosis extensa, manejo en cámara hiperbárica.

- Conocer la anatomía, aspirar antes de aplicar un medicamento intramuscular y no aplicar más de $5 \mathrm{~mL}$ del medicamento son claves importantes para prevenir el síndrome de Nicolau. 


\section{DISCUSIÓN}

El síndrome de Nicolau es una vasculopatía poco frecuente que se produce generalmente como consecuencia de la aplicación intramuscular de un fármaco (1), aunque se ha descrito también después de inyecciones subcutáneas, intravenosas, intraarticulares e intramatriciales ${ }^{(2)}$. Fue descrito inicialmente en 1924 en pacientes con sífilis que eran tratados con sales de bismuto, y desde entonces se han reportado varios casos, usualmente seguidos a la administración de penicilina, corticosteroides, antiinflamatorios no esteroideos, vacunas y otros medicamentos menos frecuentes (3).

La presentación clínica característica consiste en dolor alrededor del sitio de la inyección, asociado a eritema, a una placa de dermatitis livedoide y necrosis de la piel, del tejido subcutáneo o del tejido muscular ${ }^{(4)}$.

Su causa no está del todo clara, pero se cree que es producida por la aplicación accidental del medicamento en el área perivascular o intravascular, lo que lleva a vasoespasmo y trombosis intravascular, con posterior isquemia y necrosis localizada, que puede extenderse y dejar secuelas ${ }^{(1)}$.

El diagnóstico del síndrome de Nicolau es fundamentalmente clínico y puede estar descritas algunas complicaciones, como las deformidades por contracturas, la cicatrización anormal, la pérdida de la extremidad y la muerte.

El tratamiento varía en la literatura y dado que es una patología poco frecuente, no hay un consenso sobre su manejo. Está descrito desde el manejo conservador con antibióticos orales o intravenosos, con analgésicos, con vasoactivos como la pentoxifilina, la heparina subcutánea, los antiinflamatorios y el uso de corticosteroides (5, 6), hasta el manejo quirúrgico y con cámara hiperbárica para el manejo de las heridas extensas ${ }^{(7)}$. Aun así, en ocasiones no es posible prevenir las secuelas de esta complicación, por lo cual es fundamental un diagnóstico temprano para mejorar el pronóstico.

\section{CONCLUSIÓN}

El síndrome de Nicolau es una patología prevenible, por lo tanto, es importante que cuando se aplique un medicamento por vía parenteral se haga por personal entrenado y con una técnica adecuada. Conocer la ana- tomía, usar la aguja adecuada para el procedimiento, aspirar la jeringa para reducir el riesgo de inyección intraarterial, no aplicar más de $5 \mathrm{~mL}$ de medicamento para evitar la compresión vascular y variar el sitio de inyección en caso de que sean necesarias múltiples aplicaciones del fármaco ${ }^{(8)}$ son conductas que deben realizarse antes de aplicar un medicamento intramuscular.

\section{REFERENCIAS}

1. Dorado Fernández M, Salas García T, López Gómez A, Martínez Díaz F, Ramírez Andreo A, HernándezGil-Sánchez J, et al. Embolia cutis medicamentosa tras inyección de acetato de glatirámero. Presentación de un caso en un varón de 48 años. Piel (Barc). 2015;30(4):215-7. doi: 10.1016/j.piel.2014.12.003

2. Grover C, Kharghoria G, Daulatabad D, Bhattacharya SN. Nicolau syndrome following intramatricial triamcinolone injection for nail lichen planus. Indian Dermatol Online J. 2017;8(5):350-1. doi: 10.4103/idoj.IDOJ_333_16

3. Senel E. Nicolau syndrome as an avoidable complication. J Family Community Med. 2012;19(1):52-3. doi: 10.4103/2230-8229.94017

4. Kim SK, Kim TH, Lee KC. Nicolau syndrome after intramuscular injection: 3 cases. Arch Plast Surg. 2012;39(3):249-52. doi: 10.5999/aps.2012.39.3.249

5. Adil M, Amin SS, Arif T. Nicolau's syndrome: A rare but preventable iatrogenic disease. Acta Dermatovenerol Croat. 2017;25(3):251-3.

6. Tierce ML, Schultz SM, Lanier BQ. Tissue loss with subcutaneous immunotherapy--Nicolau syndrome. J Allergy Clin Immunol Pract. 2016;4(1):154-5. doi: 10.1016/j.jaip.2015.07.014

7. Ergul Y, Soydemir D, Tastan Y, Omeroglu RE. Does early hyperbaric oxygen therapy prevent extremity necrosis in Nicolau syndrome? Pediatr Int. 2012;54(3):e15-e18. doi: 10.1111/j.1442200X.2011.03475.X

8. Lie C, Leung F, Chow SP. Nicolau syndrome following intramuscular diclofenac administration: A case report. J Orthop Surg (Hong Kong). 200614(1):104-7. doi: 10.1177/230949900601400123 